\title{
Prolactin serum levels and breast cancer: relationships with risk factors and tumour characteristics among pre- and postmenopausal women in a population-based case-control study from Poland
}

\begin{abstract}
JM Faupel-Badger*, , ME Sherman ${ }^{2}$, M Garcia-Closas ${ }^{2}$, MM Gaudet ${ }^{3}$, RT Falk ${ }^{2}$, A Andaya ${ }^{2}$, RM Pfeiffer ${ }^{4}$, XR Yang ${ }^{5}$, J Lissowska ${ }^{6}$, LA Brinton ${ }^{2}$, B Peplonska ${ }^{7}$, BK Vonderhaar ${ }^{8}$ and JD Figueroa ${ }^{2}$

'Cancer Prevention Fellowship Program, Center for Cancer Training, National Cancer Institute, 6I 20 Executive Blvd (EPS), Suite I50E, MSC 7 I05, Bethesda, MD 20892, USA; ${ }^{2}$ Hormonal and Reproductive Epidemiology Branch, Division of Cancer Epidemiology and Genetics, National Cancer Institute, Bethesda, MD 20892, USA; ${ }^{3}$ Department of Epidemiology and Population Health, Albert Einstein College of Medicine, New York, NY I046I, USA; ${ }^{4}$ Biostatistics Branch, Division of Cancer Epidemiology and Genetics, National Cancer Institute, Bethesda, MD 20892, USA; ${ }^{5}$ Genetic Epidemiology Branch, Division of Cancer Epidemiology and Genetics, National Cancer Institute, Bethesda, MD 20892, USA; ${ }^{6}$ Department of Cancer Epidemiology and Prevention, Cancer Center and M. Sklodowska-Curie Institute of Oncology, Warsaw, Poland; ' Department of Occupational and Environmental Epidemiology, Nofer Institute of Occupational Medicine, Lódź, Poland; ' ${ }^{8}$ Mammary Biology and Tumorigenesis Laboratory, Center for Cancer Research, National Cancer Institute, Bethesda, MD 20892, USA
\end{abstract}

BACKGROUND: Previous prospective studies have found an association between prolactin (PRL) levels and increased risk of breast cancer. Using data from a population-based breast cancer case-control study conducted in two cities in Poland (2000-2003), we examined the association of PRL levels with breast cancer risk factors among controls and with tumour characteristics among the cases.

METHODS: We analysed PRL serum levels among 773 controls without breast cancer matched on age and residence to 776 invasive breast cancer cases with available pretreatment serum. Tumours were centrally reviewed and prepared as tissue microarrays for immunohistochemical analysis. Breast cancer risk factors, assessed by interview, were related to serum PRL levels among controls using analysis of variance. Mean serum PRL levels by tumour characteristics are reported. These associations also were evaluated using polytomous logistic regression.

RESULTS: Prolactin levels were associated with nulliparity in premenopausal $(P=0.05)$ but not in postmenopausal women. Associations in postmenopausal women included an inverse association with increasing body mass index $(P=0.0008)$ and direct association with use of recent/current hormone therapy $(P=0.0006)$. In case-only analyses, higher PRL levels were more strongly associated with lobular compared with ductal carcinoma among postmenopausal women $(P=0.02)$. Levels were not different by tumour size, grade, node involvement or oestrogen receptor, progesterone receptor, or human epidermal growth factor receptor 2 status.

CONCLUSIONS: Our analysis demonstrates that PRL levels are higher among premenopausal nulliparous as compared with parous women. Among postmenopausal women, levels were higher among hormone users and lower among obese women. These results may have value in understanding the mechanisms underlying several breast cancer risk factor associations.

British Journal of Cancer (2010) 103, 1097-I 102. doi:I0.1038/sj.bjc.6605844 www.bjcancer.com

Published online 24 August 2010

(c) 2010 Cancer Research UK

Keywords: lobular carcinoma; molecular subtypes; prolactin; breast cancer

Prolactin (PRL) is a peptide hormone implicated in growth and differentiation of breast epithelial cells (Das and Vonderhaar, 1997; Maus et al, 1999; Vonderhaar, 1999; Clevenger et al, 2003). A recent analysis of women from the Nurses' Health Study (NHS) I and II found that higher PRL levels were associated with breast cancer risk, irrespective of menopausal status $(\mathrm{RR}=1.3,95 \%$ confidence interval $(\mathrm{CI}) 1.1-1.6, P_{\text {het }}=0.95$ ) (Tworoger et al,

*Correspondence: Dr JM Faupel-Badger; E-mail: badgerje@mail.nih.gov Received 8 July 2010; revised I5 July 2010; accepted I5 July 2010; published online 24 August 2010 2007a). Previous, smaller case-control and prospective studies (12-71 cases) have generated mixed results regarding the association of PRL levels with breast cancer (Clevenger et al, 2003).

Cumulative data have shown parous women to have $15-50 \%$ lower PRL levels than nulliparous women, with the majority of this decrease following the first full-term pregnancy (Musey et al, 1987; Wang et al, 1988; Ingram et al, 1990; Eliassen et al, 2007). The associations of PRL levels with other known breast cancer risk factors, including: age at menarche and first birth, benign breast disease, and adult body weight, have mostly been null for both pre- and postmenopausal women, even after adjusting for parity 
(Kwa et al, 1976, 1981; Wang et al, 1988; Tworoger et al, 2006a; Eliassen et al, 2007; Su et al, 2009).

Conclusions regarding the associations of PRL with breast cancer risk factors and tumour characteristics are largely based on a small number of studies and, in some cases, small populations. Accordingly, further assessment of risk related to PRL levels by patient and tumour characteristics is needed. Using a large population-based case-control study conducted in Poland, we explored the association of PRL levels with known breast cancer risk factors in both pre- and postmenopausal women in our control population. We also examined associations of serum PRL levels with tumour characteristics among the incident cases of breast cancer.

\section{MATERIALS AND METHODS}

Details regarding the population and design of the Polish casecontrol study have been reported elsewhere (Garcia-Closas et al, 2006). Subjects provided written informed consent and the study protocol was approved by ethical boards in Poland and the United States. Briefly, eligible cases were women ages 20-74 years with pathologically confirmed breast cancer living in Warsaw or Lodz, Poland and diagnosed from 2000 to 2003. The Polish Electronic System, a database with demographic information from all residents of Poland, was used to randomly select controls, defined as women without breast cancer, frequency matched to cases on city and age in 5-year categories. In total, $79 \%$ of eligible cases (2386) and 69\% of eligible controls (2502) consented to participate in an interview regarding breast cancer risk factors. Of these women, $84 \%$ of cases and $92 \%$ of controls agreeing to the interview provided blood samples. Paraffin-embedded tumour tissue was collected from $87 \%$ of cases.

Of 2386 eligible cases with questionnaire data, we selected the subset with invasive cancer tissue prepared as tissue microarrays (TMAs) $(N=1477)$. Serum samples were available from 1155 of these women. We excluded women treated before collection of blood $(n=353)$ or tumour tissue $(n=23)$, resulting in 779 cases for PRL serum analyses. Controls were matched to cases on menopausal status, age (in 5-year increments), time of day of blood draw (within $2 \mathrm{~h}$ ), study site, and, for premenopausal women, day in menstrual cycle ( \pm 2 days).

Prolactin was measured by Quest Diagnostics (San Juan Capistrano, CA, USA) using an immunoassay and concentrations calculated by the ADVIA Centaur instrument (Bayer HealthCare, Tarrytown, NY, USA), which was calibrated with known PRL concentrations. Approximately $3 \%$ of samples that included low, medium and high levels of PRL were retested in masked fashion to assess intra- and interbatch variation. The overall coefficient of variation for the PRL serum assay was $<5 \%$ and the intraclass correlation coefficient was $>99 \%$.

Histopathologic features including histology, grade, tumour size, and axillary lymph node metastases were assessed using surgical pathology reports. Tumour features were independently evaluated by the study pathologist (MES). Results for immunohistochemical stains for oestrogen receptor (ER), progesterone receptor (PR), and human epidermal growth factor receptor 2 (HER2) from the invasive cancers, prepared as TMAs with duplicate representation as $0.6-\mathrm{mm}$ diameter cores (Beecher Instruments, Silver Spring, MD, USA), were determined as reported previously (Sherman et al, 2007; Yang et al, 2007a, b).

\section{Statistical analysis}

Associations between subjects' demographic and breast cancer risk factors and serum PRL levels were assessed using $T$-test (continuous) and $\chi^{2}$ analyses (categorical). Analyses were based on natural log transformation of serum PRL levels. The association of PRL concentrations with known risk factors was evaluated among controls using analysis of variance. Details of the entire Poland breast cancer case-control study population with questionnaire data have been reported previously (Garcia-Closas et al, 2006).

To determine if serum PRL levels varied by important tumour characteristics, we initially performed polytomous logistic regression to estimate odds ratios (OR) and 95\% CI for PRL serum levels with the relevant tumour characteristics as the outcome variables. The final models adjusted for the following variables: time of blood collection in 2-h categories, years of education, age at menarche $(\leqslant 12,13,14,15$, and $\geqslant 16)$, age at menopause $(<45,45-49$, and $\geqslant 50-54)$, number of full-term births $(0,1,2$, or $3+)$, age at first full-term birth $(<20,20-24,25-29$, and $\geqslant 30)$, family history of breast cancer among first-degree relatives, previous breast disease (history of a benign breast biopsy 1 year before date of diagnosis for cases and date of interview for controls), body mass index (BMI) $\left(<25,25-29.9\right.$, and $\left.\geqslant 30 \mathrm{~kg} \mathrm{~m}^{-2}\right)$, age in 5-year categories, and study site. For premenopausal women, the additional matching variable of menstrual status was also adjusted for in models. For postmenopausal women, models were also adjusted for oral hormone replacement therapy (HRT) use (current/recent use, past use, and ever used oestrogens or combined oestrogen/ progestin). Never users of oral HRT were those individuals who used oral HRT for 1 month or less and, among users, current/ recent users were those for whom it had been 2 years or less since last use and past users were those for whom the last use was $>2$ years ago. $P$-values to test for heterogeneity of ORs between tumour characteristics were calculated using logistic regression analyses restricted to cases with the relevant tumour characteristic as the outcome and PRL serum hormone levels as the explanatory variable. Mean serum PRL levels across important tumour characteristics are reported to illustrate the relationship between serum PRL levels and breast cancer histology.

In Supplementary Table 2, we report the associations of breast cancer; with PRL levels, recognising the limitation that blood measurements among patients may reflect disease effects or acute stress responses. For these reasons, this analysis was limited to individuals who had PRL levels within the normal range (i.e., $\left.\leqslant 30 \mathrm{ng} \mathrm{ml}^{-1}\right)$, which excluded $4 \%(n=19)$ of the premenopausal population and $3 \%(n=35)$ of the postmenopausal from the analysis. PRL levels were significantly different between premenopausal and postmenopausal controls. Therefore, separate quartiles were established for pre- and postmenopausal women using the distributions from the control population. For premenopausal women the quartiles were $\leqslant 7.70,7.71-10.20,10.21-15.00$, and $>15.00 \mathrm{ng} \mathrm{ml}^{-1}$. For postmenopausal women the quartiles were $\leqslant 5.30,5.31-6.70,6.71-8.40$, and $>8.40 \mathrm{ng} \mathrm{ml}^{-1}$. To estimate the association between PRL serum levels and breast cancer risk, we used conditional logistic regression models separately for pre- and postmenopausal women, as described above for the analysis with tumour characteristics, to compute OR and $95 \%$ CIs. Statistical significance was defined as two-sided $P<0.05$ and all analyses were completed with SAS (version 9.0, SAS Institute, Inc., Cary, NC, USA) or STATA (version 9.0, STATA Corporation, College Station, TX, USA) software.

\section{RESULTS}

\section{Characteristics of study population}

The study population consisted of 230 premenopausal and 543 postmenopausal breast cancer cases and an equal number of matched controls. The mean age was approximately $45( \pm 5.3)$ years old for premenopausal women and $61( \pm 7.7)$ years old for postmenopausal women. With respect to breast cancer risk factors and tumour characteristics, the distributions for the population selected for the analyses presented herein (data not shown) did not 
significantly differ from the entire Poland breast cancer casecontrol parent population (Garcia-Closas et al, 2006; Yang et al, 2007a). Means and frequencies for several breast cancer risk factors are presented in Supplementary Table 1.

\section{PRL and associations with risk factors among controls in pre- and postmenopausal women}

The association of PRL levels with established breast cancer risk factors was examined among controls. Geometric mean PRL levels were $10.9 \mathrm{ng} \mathrm{ml}^{-1}$ in premenopausal controls and $7.0 \mathrm{ng} \mathrm{ml}^{-1}$ in postmenopausal controls (Table 1). Among premenopausal women, nulliparous women had marginally significantly higher levels of PRL than parous women (mean 13.67 and $10.67 \mathrm{ng} \mathrm{ml}^{-1}$, respectively, $P=0.05$ ) (Table 1 ). Other comparisons of strata for menstrual and reproductive factors, personal history of benign breast disease and family history were not related to significant differences in PRL levels. Among postmenopausal women, increasing BMI was associated with lower PRL levels $(P=0.0008)$. In separate analyses of height and current weight, height was positively associated $(P=0.04)$ and current weight was inversely associated $(P=0.01)$ with serum PRL levels in postmenopausal women (data not shown), suggesting that the association with current weight is the dominant factor in the inverse association of PRL levels with BMI.

With regard to oral contraceptive use, this population included only 10 current and 28 former premenopausal oral contraceptive users, precluding a meaningful analysis of the relationship of use to PRL levels. Among postmenopausal controls, women currently using HRT had significantly higher PRL levels than never or

Table I Established breast cancer risk factors and PRL serum levels among 773 population controls in the Polish Breast Cancer Study

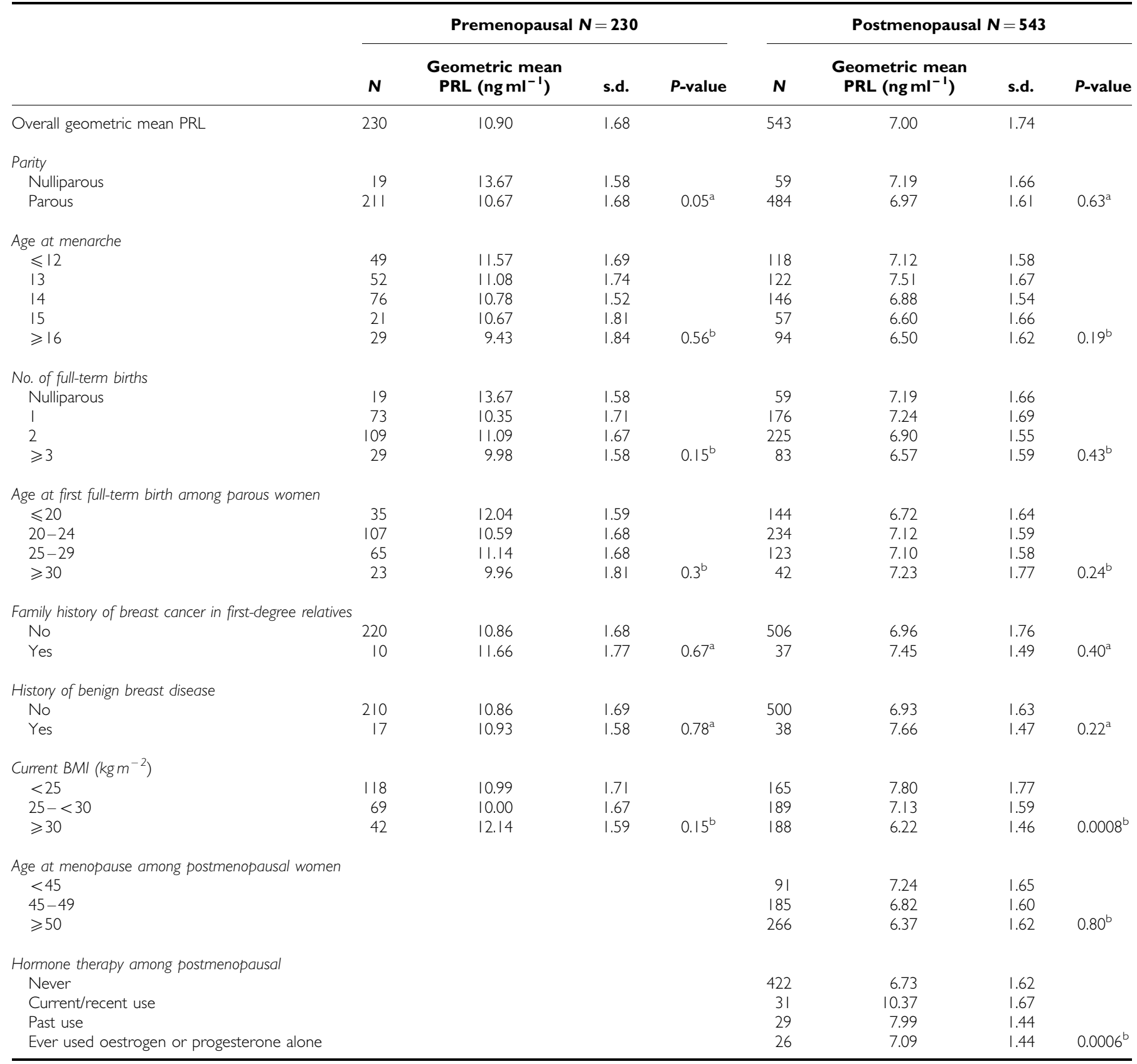

Abbreviations: ANOVA = analysis of variance; BMI = body mass index; PRL = prolactin. ${ }^{\text {a }}$-values from $t$-test. ${ }^{b}$-values from ANOVA. 
former users $(P=0.0006)$. After mutually adjusting for BMI and HRT, the associations of serum PRL levels with BMI and HRT were still significant ( $P=0.0036$ and $P=0.0028$, respectively).

\section{PRL levels and tumour characteristics in pre- and postmenopausal women}

In Supplementary Table 2, we report the association of PRL levels with risk of breast cancer. Among postmenopausal women, higher PRL levels were associated with increased risk of breast cancer $(\mathrm{OR}=1.76,95 \% \mathrm{CI}: 1.21-2.57, P=0.003)$ when comparing the highest with the lowest PRL quartile and, among premenopausal women, PRL levels were not associated with increased breast cancer risk.

We further evaluated the association of PRL levels with clinically important tumour characteristics among cases (Table 2). In postmenopausal women, lobular histology was associated with higher levels of PRL than ductal histology $(P=0.02$, Table 2); removing HRT users from the analysis yielded similar conclusions $(P=0.03)$. This difference in PRL levels translated into a stronger risk association for lobular $(\mathrm{OR}=3.04,95 \% \mathrm{CI}$ : $1.81-5.91)$ than ductal $(\mathrm{OR}=1.62,95 \%$ CI: $1.18-2.23)$ tumours. No other significant differences in PRL levels were noted across the tumour characteristics of tumour grade, size, node involvement, and ER, PR, or HER2 expression.

\section{DISCUSSION}

Our analysis of serum PRL levels among population-based controls in the Polish study demonstrated significant relationships with three established breast cancer risk factors: nulliparity, among premenopausal women, and HRT and BMI among postmenopausal women. Consistent with previous reports, we found that PRL levels among parous premenopausal women were lower than those among nulliparous women (Musey et al, 1987; Eliassen et al, 2007). In addition, among premenopausal parous women, levels declined slightly with increasing parity. However, we did not find an association between parity and PRL concentrations among postmenopausal, which contrasts with some reports (Wang et al, 1988; Eliassen et al, 2007). Lowered PRL levels have been suggested as one of several possible mechanisms that mediate this risk.

In this study, PRL levels were inversely associated with BMI among postmenopausal women, whereas other analyses have shown null (Kwa et al, 1976; Tworoger et al, 2007b; Su et al, 2009) or positive associations (Wang et al, 1988; McTiernan et al, 2006). Postmenopausal obesity is associated with higher circulating oestrogen levels and increased breast cancer risk in many studies (Key et al, 2001). Given that the PRL gene contains an oestrogen response element and that in vitro oestrogen upregulates expression of PRL (Duan et al, 2008), our inverse association is unexpected. However, in previous analyses from this study, postmenopausal obesity was associated only with larger tumours, rather than breast

Table 2 Geometric mean PRL serum levels stratified by clinically important tumour characteristics in the Polish Breast Cancer Study

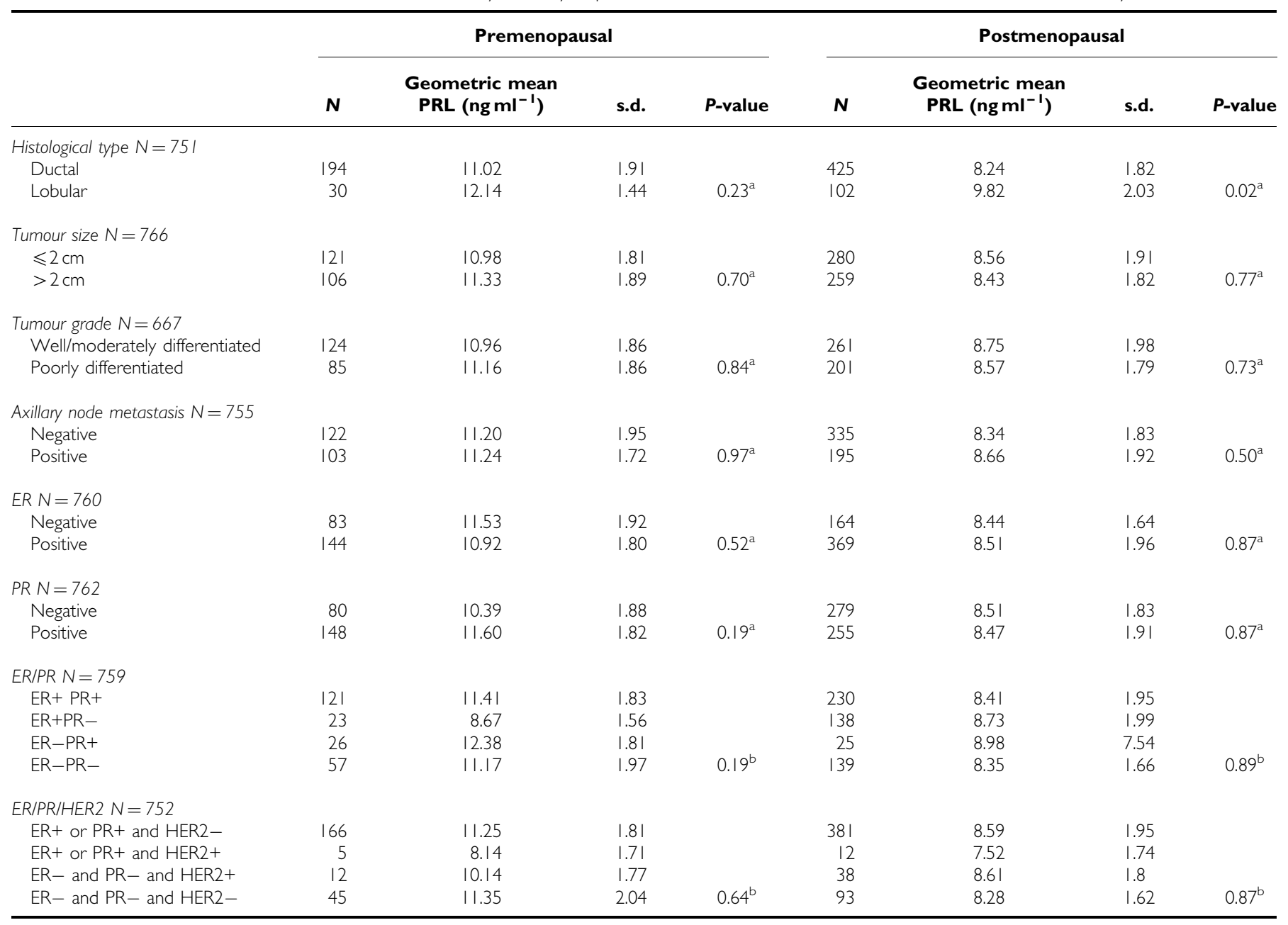

Abbreviations: ANOVA = analysis of variance; $E R=$ oestrogen receptor; HER2 = human epidermal growth factor receptor 2; PR= progesterone receptor; PRL = prolactin.

a $P$-values from $t$-test. ${ }^{\text {b }}$-values from ANOVA. 
cancer overall (Garcia-Closas et al, 2006), so the subject requires further investigation, ideally by considering distribution of adiposity and concurrent measurements of serum oestrogens.

Although there have been reports demonstrating a positive association of oral contraceptive use with PRL levels (Mishell et al, 1977; Scott et al, 1978; Clevenger et al, 2003), the data regarding HRT are largely null (Castelo-Branco et al, 1995; Foth and Romer, 1997; Schlegel et al, 1999; Molitch, 2008). In our population, use of both oral contraceptives and HRT were uncommon compared with the United States. Nonetheless, recent/current HRT in the Polish study was significantly associated with higher PRL levels in postmenopausal women. Mutual adjustment of BMI and HRT did not alter these interpretations substantively; both lower BMI and HRT remained related to PRL concentrations. However, these findings need careful interpretation as analyses were based on small numbers of users.

Previous data have suggested that a positive family history of breast cancer may be related to higher PRL levels, especially among premenopausal women (Hankinson et al, 1995; Clevenger et al, 2003; Eliassen et al, 2007). Similarly, we observed increased risk related to increased levels of PRL among women with a family history of breast cancer, but women with a positive family history were relatively uncommon in this data set and results were not statistically significant. Associations of PRL levels with benign breast disease have been mixed and may depend on the particular underlying pathologic condition leading to the development of benign breast disease (Courtillot et al, 2005). We did not find an association in Poland, but screening was less common than in some other populations.

In addition, we examined the association of serum PRL levels with tumour characteristics. We did not find significant difference in geometric mean PRL levels by either tumour size or the presence of lymph node metastases, suggesting that PRL levels may not be related to time of clinical diagnosis. In this population, we did identify a stronger relationship between high PRL levels and postmenopausal invasive lobular carcinoma. This finding is interesting and in contrast to previous reports in which no heterogeneity between invasive ductal and lobular cancers was detected (Tworoger et al, 2007a). Some previous reports have suggested a relationship between HRT and risk of lobular cancer (Li et al, 2008). Our finding of the association of higher PRL levels with invasive lobular carcinoma was independent of HRT use.

Prolactin levels were not related to ER, PR, or HER2 status. These data did not replicate the finding from NHS I and II where the association with PRL was stronger among ER $+/ \mathrm{PR}+$ tumours (Tworoger et al, 2007a). Our study was truncated at age 74 years and in a largely unscreened population; therefore, the characteristics of our postmenopausal $\mathrm{ER}+/ \mathrm{PR}+$ cancers may have differed from the NHS. Apart from this analysis, knowledge about relationships of PRL levels and HER2 status are limited and further studies are necessary.

The analyses presented herein have some limitations. Notably, our case-control results must be interpreted with caution as PRL is a stress hormone and we cannot exclude that the relationship with breast cancer was influenced by a stress responses (Freeman et al, 2000). In addition, breast tumour cells have been shown to synthesise and secrete PRL in cell culture models (Ginsburg and Vonderhaar, 1995). If PRL levels were affected by tumours or patient stresses, our case-control estimates might be inflated; however, our case-control associations are generally similar to those found in NHS (Tworoger et al, 2007a).
In this study, PRL also was measured by an immunoassay that does not discriminate between PRL isoforms, some of which are reported to have varying biological activity (Freeman et al, 2000). Regardless, this immunoassay is a widely accepted method for measuring PRL in clinical and epidemiology studies and is currently the only method that can be easily applied to large population-based studies. Our choice of immunoassay also provides the opportunity for our results to be compared with those obtained by others (Hankinson et al, 1999; Tworoger et al, 2004, 2006b, 2007a). Finally, high mammographic density, which is perhaps the strongest risk factor for non-familial breast cancer apart from age and gender, has been associated with higher PRL levels in some (Boyd et al, 2002) but not all (Tamimi et al, 2005; Johansson et al, 2008) studies. We did not have the ability to examine the association of PRL levels with mammographic density in the current analyses.

The strengths of this study include its population-based design, and extensive collection of risk factor, pathologic and immunohistochemical data. Our analyses were based on incident cases from whom serum was collected at the time of diagnosis of breast cancer. In addition, PRL measurements have been shown to be reliable and most likely a reflection of cumulative exposure over time (Missmer et al, 2006; Arslan et al, 2008; Tworoger and Hankinson, 2008; Kotsopoulos et al, 2010), and hence can be considered a stable marker of exposure and potentially risk. We found that elevated PRL levels were associated with selected breast cancer risk factors and, with the caveats outlined above, also increased breast cancer risk among postmenopausal women. Consistent with previous prospective studies (Tworoger et al, 2004) and case-control studies summarised in a recent review (Tworoger and Hankinson, 2008), we found that PRL levels were unrelated to two factors reflecting progression, tumour size, and lymph node metastases. In conclusion, our data suggest that PRL levels may be related to several breast cancer risk factors and could potentially have value in understanding the mechanisms that mediate these factors. Accordingly, continued study of the importance of PRL in breast cancer is warranted.

\section{ACKNOWLEDGEMENTS}

We thank Drs Neonila Szeszenia-Dabrowska of the Nofer Institute of Occupational Medicine (Lodz, Poland), Witold Zatonski of the Department of Cancer Epidemiology and Prevention, the M Sklodowska-Curie Cancer Center and Institute of Oncology (Warsaw, Poland), and Pei Chao and Michael Stagner from Information Management Services (Sliver Spring, MD, USA), for their valuable contributions to the study. We also thank the participants, physicians, pathologists, nurses, and interviewers from participating centres in Poland for their efforts during field-work. The study was funded by Intramural Research Funds of the National Cancer Institute, Department of Health and Human Services, USA. This research was supported by the Intramural Research Programs of the Division of Cancer Epidemiology and Genetics and Center for Cancer Research of the National Cancer Institute. Dr FaupelBadger's research also was supported by the Cancer Prevention Fellowship Program, Center for Cancer Training, NCI.

Supplementary Information accompanies the paper on British Journal of Cancer website (http://www.nature.com/bjc)

\section{REFERENCES}

Arslan AA, Gu Y, Zeleniuch-Jacquotte A, Koenig KL, Liu M, Velikokhatnaya L, Shore RE, Toniolo P, Linkov F, Lokshin AE (2008) Reproducibility of serum pituitary hormones in women. Cancer Epidemiol Biomarkers Prev 17: $1880-1883$ 
Boyd NF, Stone J, Martin LJ, Jong R, Fishell E, Yaffe M, Hammond G, Minkin S (2002) The association of breast mitogens with mammographic densities. Br J Cancer 87: 876-882

Castelo-Branco C, Martinez de Osaba MJ, Fortuny A, Iglesias X, Gonzalez-Merlo J (1995) Circulating hormone levels in menopausal women receiving different hormone replacement therapy regimens. A comparison. J Reprod Med 40: 556-560

Clevenger CV, Furth PA, Hankinson SE, Schuler LA (2003) The role of prolactin in mammary carcinoma. Endocr Rev 24: 1-27

Courtillot C, Plu-Bureau G, Binart N, Balleyguier C, Sigal-Zafrani B, Goffin V, Kuttenn F, Kelly PA, Touraine P (2005) Benign breast diseases. J Mammary Gland Biol Neoplasia 10: 325-335

Das R, Vonderhaar BK (1997) Prolactin as a mitogen in mammary cells. J Mammary Gland Biol Neoplasia 2: 29-39

Duan R, Ginsburg E, Vonderhaar BK (2008) Estrogen stimulates transcription from the human prolactin distal promoter through AP1 and estrogen responsive elements in T47D human breast cancer cells. Mol Cell Endocrinol 281: 9-18

Eliassen AH, Tworoger SS, Hankinson SE (2007) Reproductive factors and family history of breast cancer in relation to plasma prolactin levels in premenopausal and postmenopausal women. Int J Cancer 120: $1536-1541$

Foth D, Romer T (1997) Prolactin serum levels in postmenopausal women receiving long-term hormone replacement therapy. Gynecol Obstet Invest 44: $124-126$

Freeman ME, Kanyicska B, Lerant A, Nagy G (2000) Prolactin: structure, function, and regulation of secretion. Physiol Rev 80: 1523-1631

Garcia-Closas M, Brinton LA, Lissowska J, Chatterjee N, Peplonska B, Anderson WF, Szeszenia-Dabrowska N, Bardin-Mikolajczak A, Zatonski W, Blair A, Kalaylioglu Z, Rymkiewicz G, Mazepa-Sikora D, Kordek R, Lukaszek S, Sherman ME (2006) Established breast cancer risk factors by clinically important tumour characteristics. $\mathrm{Br} J$ Cancer 95: $123-129$

Ginsburg E, Vonderhaar BK (1995) Prolactin synthesis and secretion by human breast cancer cells. Cancer Res 55: 2591-2595

Hankinson SE, Colditz GA, Hunter DJ, Manson JE, Willett WC, Stampfer MJ, Longcope C, Speizer FE (1995) Reproductive factors and family history of breast cancer in relation to plasma estrogen and prolactin levels in postmenopausal women in the Nurses' Health Study (United States). Cancer Causes Control 6: 217-224

Hankinson SE, Willett WC, Michaud DS, Manson JE, Colditz GA, Longcope C, Rosner B, Speizer FE (1999) Plasma prolactin levels and subsequent risk of breast cancer in postmenopausal women. J Natl Cancer Inst 91: 629-634

Ingram DM, Nottage EM, Roberts AN (1990) Prolactin and breast cancer risk. Med J Aust 153: 469-473

Johansson H, Gandini S, Bonanni B, Mariette F, Guerrieri-Gonzaga A, Serrano D, Cassano E, Ramazzotto F, Baglietto L, Sandri MT, Decensi A (2008) Relationships between circulating hormone levels, mammographic percent density and breast cancer risk factors in postmenopausal women. Breast Cancer Res Treat 108: 57-67

Key TJ, Allen NE, Verkasalo PK, Banks E (2001) Energy balance and cancer: the role of sex hormones. Proc Nutr Soc 60: 81-89

Kotsopoulos J, Tworoger SS, Campos H, Chung FL, Clevenger CV, Franke AA, Mantzoros CS, Ricchiuti V, Willett WC, Hankinson SE, Eliassen AH (2010) Reproducibility of plasma and urine biomarkers among premenopausal and postmenopausal women from the Nurses' Health Studies. Cancer Epidemiol Biomarkers Prev 19: 938-946

Kwa HG, Cleton F, Bulbrook RD, Wang DY, Hayward JL (1981) Plasma prolactin levels and breast cancer: relation to parity, weight and height, and age at first birth. Int J Cancer 28: 31-34

Kwa HG, Cleton F, de Jong-Bakker M, Bulbrook RD, Hayward JL, Wang DY (1976) Plasma prolactin and its relationship to risk factors in human breast cancer. Int J Cancer 17: 441-447

Li CI, Malone KE, Porter PL, Lawton TJ, Voigt LF, Cushing-Haugen KL, Lin MG, Yuan X, Daling JR (2008) Relationship between menopausal hormone therapy and risk of ductal, lobular, and ductal-lobular breast carcinomas. Cancer Epidemiol Biomarkers Prev 17: 43-50

Maus MV, Reilly SC, Clevenger CV (1999) Prolactin as a chemoattractant for human breast carcinoma. Endocrinology 140: 5447-5450

McTiernan A, Wu L, Chen C, Chlebowski R, Mossavar-Rahmani Y, Modugno F, Perri MG, Stanczyk FZ, Van Horn L, Wang CY (2006)
Relation of BMI and physical activity to sex hormones in postmenopausal women. Obesity (Silver Spring) 14: $1662-1677$

Mishell Jr DR, Kletzky OA, Brenner PF, Roy S, Nicoloff J (1977) The effect of contraceptive steroids on hypothalamic-pituitary function. Am J Obstet Gynecol 128: $60-74$

Missmer SA, Spiegelman D, Bertone-Johnson ER, Barbieri RL, Pollak MN, Hankinson SE (2006) Reproducibility of plasma steroid hormones, prolactin, and insulin-like growth factor levels among premenopausal women over a 2- to 3-year period. Cancer Epidemiol Biomarkers Prev 15: 972-978

Molitch ME (2008) Drugs and prolactin. Pituitary 11: 209-218

Musey VC, Collins DC, Musey PI, Martino-Saltzman D, Preedy JR (1987) Long-term effect of a first pregnancy on the secretion of prolactin. $N$ Engl J Med 316: 229-234

Schlegel W, Petersdorf LI, Junker R, Schulte H, Ebert C, Von Eckardstein A (1999) The effects of six months of treatment with a low-dose of conjugated oestrogens in menopausal women. Clin Endocrinol (Oxf) 51: $643-651$

Scott JZ, Kletzky OA, Brenner PF, Mishell Jr DR (1978) Comparison of the effects of contraceptive steroid formulations containing two doses of estrogen on pituitary function. Fertil Steril 30: $141-145$

Sherman ME, Rimm DL, Yang XR, Chatterjee N, Brinton LA, Lissowska J, Peplonska B, Szeszenia-Dabrowska N, Zatonski W, Cartun R, Mandich D, Rymkiewicz G, Ligaj M, Lukaszek S, Kordek R, Kalaylioglu Z, Harigopal M, Charrette L, Falk RT, Richesson D, Anderson WF, Hewitt SM, Garcia-Closas M (2007) Variation in breast cancer hormone receptor and HER2 levels by etiologic factors: a population-based analysis. Int J Cancer 121: 1079-1085

Su X, Hankinson SE, Clevenger CV, Eliassen AH, Tworoger SS (2009) Energy balance, early life body size, and plasma prolactin levels in postmenopausal women. Cancer Causes Control 20: 253-262

Tamimi RM, Hankinson SE, Colditz GA, Byrne C (2005) Endogenous sex hormone levels and mammographic density among postmenopausal women. Cancer Epidemiol Biomarkers Prev 14: 2641-2647

Tworoger SS, Eliassen AH, Missmer SA, Baer H, Rich-Edwards J, Michels KB, Barbieri RL, Dowsett M, Hankinson SE (2006a) Birthweight and body size throughout life in relation to sex hormones and prolactin concentrations in premenopausal women. Cancer Epidemiol Biomarkers Prev 15: 2494-2501

Tworoger SS, Eliassen AH, Rosner B, Sluss P, Hankinson SE (2004) Plasma prolactin concentrations and risk of postmenopausal breast cancer. Cancer Res 64: 6814-6819

Tworoger SS, Eliassen AH, Sluss P, Hankinson SE (2007a) A prospective study of plasma prolactin concentrations and risk of premenopausal and postmenopausal breast cancer. J Clin Oncol 25: 1482-1488

Tworoger SS, Hankinson SE (2008) Prolactin and breast cancer etiology: an epidemiologic perspective. J Mammary Gland Biol Neoplasia 13: 41-53

Tworoger SS, Sluss P, Hankinson SE (2006b) Association between plasma prolactin concentrations and risk of breast cancer among predominately premenopausal women. Cancer Res 66: 2476-2482

Tworoger SS, Sorensen B, Chubak J, Irwin M, Stanczyk FZ, Ulrich CM, Potter J, McTiernan A (2007b) Effect of a 12-month randomized clinical trial of exercise on serum prolactin concentrations in postmenopausal women. Cancer Epidemiol Biomarkers Prev 16: 895-899

Vonderhaar BK (1999) Prolactin involvement in breast cancer. Endocr Relat Cancer 6: $389-404$

Wang DY, de Stavola BL, Bulbrook RD, Allen DS, Kwa HG, Verstraeten AA, Moore JW, Fentiman IS, Hayward JL, Gravelle IH (1988) The permanent effect of reproductive events on blood prolactin levels and its relation to breast cancer risk: a population study of postmenopausal women. Eur J Cancer Clin Oncol 24: 1225-1231

Yang XR, Pfeiffer RM, Garcia-Closas M, Rimm DL, Lissowska J, Brinton LA, Peplonska B, Hewitt SM, Cartun RW, Mandich D, Sasano H, Evans DB, Sutter TR, Sherman ME (2007a) Hormonal markers in breast cancer: coexpression, relationship with pathologic characteristics, and risk factor associations in a population-based study. Cancer Res 67: 10608-10617

Yang XR, Sherman ME, Rimm DL, Lissowska J, Brinton LA, Peplonska B, Hewitt SM, Anderson WF, Szeszenia-Dabrowska N, Bardin-Mikolajczak A, Zatonski W, Cartun R, Mandich D, Rymkiewicz G, Ligaj M, Lukaszek S, Kordek R, Garcia-Closas M (2007b) Differences in risk factors for breast cancer molecular subtypes in a population-based study. Cancer Epidemiol Biomarkers Prev 16: 439-443 